\title{
Intensive case management: putting it into practice
}

\author{
Frank Holloway, Morag Murray, Clare Squire and Jerome Carson
}

\begin{abstract}
The firs 18 months of operation of a tecm providing high intenatty case manogement is presented. A koy-worker/ co-worker syetem was adopled, with regular team meetings to reviow the progress of all clients. Low case-loads (10 clients per case manager) encbled the tean to carry out detalled asesesements of need, offer cescertive outreach and crits intervention and coordinate complox packages of community care. The cose mancosment team provided on coceselble and eflective senvice. However, not all patients appecared to bencilt and the intenatve nature of the work was very demanding on stafl.
\end{abstract}

Case management (later renamed care management) was described in the White Paper Caring for People (Secretaries of State for Health and Social Security, 1989) as a 'cornerstone' of effective community care. However, there is confusion over the meaning of the term and a surprising lack of evidence regarding its efflcacy in the care of the mentally ill (Bachrach, 1989). Core functions of case management that have been identified include the assessment of individual need, the development of a comprehenstve service plan, arrangement of service delivery, the monitoring and assessment of services and evaluation and follow-up (leading if necessary to a revised package of treatment and care) (Ryan et al, 1991). These may be described as the 'brokerage' aspects of case management. Additional possible functions of a case management service include case finding, direct service provision, crisis intervention, advocacy on behalf of the client, and the development of a supportive relationship with the client/patient. Experience in the United States suggests that effective case management services combine 'brokerage' with more traditionally 'clinical' functions (Kanter, 1989). Evidence from controlled studies, largely carried out in North America, provides some support for "clinical' case management but none for 'brokerage' (Burns \& Santos, 1995; Holloway et al, 1995; Marshall et al, 1995).

Fast Lambeth Continuing Care Team

We have been carrying out a controlled trial of 'clinical' case management versus standard care in East Lambeth, London, a highly deprtved inner urban catchment area which possesses an extensive but poorly coordinated range of social and health care resources for the mentally ill. The study recruited 'hard to treat' patients with a functional psychosis originating in the catchment area. This paper describes the work of the case management team (the East Lambeth Continuing Care Team: ELCCT) and some of the practical lessons learnt during the study.

The ELCCT was well resourced. Core team members consisted of a manager ( $H$ grade nurse) and four team members (two G grade nurses, a C grade nurse and a senior I occupational therapist). In addition, two psychiatrist and two clinical psychologist sessions were provided. Clients had access to the local hospital and community-based mental health social work teams. The ELCCT adopted a key-worker/co-worker system. although all team members had knowledge of the caseload. There were dally informal meetings between core team members regarding the caseload and a regular formal review (involving the client and significant others in the caring network).

Characteristics of the 35 ELCCT clients in the controlled study are presented in Table 1. Twenty-seven had demonstrated poor insight and engagement with services prior to referral (the remaining eight being referred on the grounds of disappointing symptomatic response to standard care). Six patients fitted the highly

Table 1. Characteristics of 35 patients recelving intensive case management

\begin{tabular}{lr}
\hline DSM-III-R dlagnosis & \\
Schizophrenla/schizoaffective psychosis & $92 \%$ \\
Bipolar affective disorder & $8 \%$ \\
Males & $66 \%$ \\
Afro-Caribbean or black Afican & $54 \%$ \\
Single/dlvorced/separated & $96 \%$ \\
Incomplete symptomatic response to treatment & $60 \%$ \\
Non-compllant with treatment in past 2 years & $77 \%$ \\
Two or more in-patient admissions & $100 \%$ \\
Mean age & 33.7 yrs \\
Years since onset of illness & 10.5 yrs \\
\hline
\end{tabular}


restrictive local criteria for inclusion on the Supervision Register (McCarthy et al, 1995).

\section{Case management in practice}

The work of the ELCCT can be summarised under four headings: engagement and assessment; direct 'clinical' work; social care; and brokerage/ advocacy. Engagement required skdll, persistence and imagination by ELCCT staff, who adopted a respectful approach to clients and offered help with practical tasks of relevance to the client. Clients who were in-patients at the point of referral to the study were supported during the process of resettlement. Meetings often took place in local cafés. Detalled information gathering provided a thorough assessment of the client's needs, including an informed assessment of risk (Department of Health, 1994), although a complex assessment tool developed by the team was abandoned in favour of a care plan covering a set of standard headings (see below).

Direct treatment included psychoeducation (discussing the illness and its implications with the client), the negotiation of treatment compliance, family interventions, cognitive-behavioural interventions aimed at decreasing the impact of distressing abnormal beliefs and experiences on the individual, and intervention in crisis (which included arranging hospital admission as necessary). ELCCT staff closely monitored compliance with medication, with nursing staff administering depot medication and often delivering oral medication to the client's home. Much of the team's work involved the provision or arrangement of social care. Staff offered basic benefits advice, provided some direct personal care, encouraged clients to participate in leisure and recreational activities and arranged appropriate day activities. The team also offered open access to the team base. A drop-in service was offered two days a week at which clients could socialise.

Brokerage and advocacy on behalf of the clients was an important aspect of the team's work. This included referral for care management (if access was required for a local authority funded service), liaison with the Department of Social Security and the Housing Department (many clients were unsatisfactorily housed or homeless, while others had built up significant rent arrears) and liaison with the general practitioner.

Staff developed a training programme which emphasised risk management, the benefits system and continuing update on local social care services. Review meetings followed the principles of the Care Programme Approach, adopting a standard agenda covering issues of mental health/medication, physical health, finances, housing, daytime activities/social networks, daily living skills and family support. The meeting was chaired by a team member and minutes were subsequently distributed to all participants, including the client (who was always invited).

\section{Outcomes}

At 18 months the team had established a model of care which, after initial scepticism, has become the pattern for the local service (albeit carried out with less resources and larger caseloads). The service had been highly effectlve at engaging clients (with only one of 35 study patients completely falling to engage). Improving the engagement of 'hard to treat' patients with the services, which many had hitherto rejected, was a major aim of the team. The combination of walkin' access and outreach provided by the team allowed contact to be retained with all study patients and appeared to alter the illness career of a number of clients who had previously challenged services. (Examples include a psychotic man with a personality disorder who had taken over 20 drug overdoses in the year prior to referral who ceased self-harming; an elderly schizophrenic woman who had required repeated in-patient admission after failed residential placements who was successfully supported in independent accommodation; and a young schizophrenic man with a history of drug abuse, violence and prolonged hospitalisation who proved capable of living in his own flat). The ELCCT made extenstve use of other health and soctal care services and was able to coordinate complex packages of health and social care.

As part of the controlled study clients' views about their care were elicited. Some of the verbatim comments of ELCCT clients give a flavour of the team's work: "They are friendly and don't treat me like a burden": "They help me with grants"; "M. doesn't agree that John the Baptist spoke to me, but she has an open mind. The doctors just think I'm mad"; "The help is much better than before. People are concerned that my day is structured properly": "She used to come to the flat, make a cup of tea and chat with me. No-one from the hospital has done that before".

Readmission was common, with a total of 20 admissions of 12 patients in 18 months. Eight patients were detained in hospital under the Mental Health Act. All admissions were under the care of the team consultant (FH). The philosophy of the team was to facilitate admission when it was felt to be necessary rather than avold it at all costs. The majority of admissions took place because of exacerbations in psychotic symptomatology, often following a period of noncompliance with medication or in relation to some identifiable psychosocial stressor. A number of respite admissions were arranged, temporary 
admission to social care resources proving impossible to negotiate locally. These respite admissions were invariably brief. Team members remained in close contact with hospitalised clients.

During the first 18 months of the study the 35 patients occupied on average 2.9 in-patient beds per day. Only five project clients made use of nonhospital residential services during the first 18 months of the project, two living in 24 hour staff hostels and three in non-staffed group homes. Fifteen clients lived with family or friends and 15 lived independently. In general, project clients aspired to live independently despite continuing symptomatology and social disability.

One patient was felt to be inappropriate for support by the team (a former armed robber with a psychotic illness complicated by oplate addiction). After a period largely out of contact with services he re-presented through the criminal justice system. Three patients required in-patient admissions over six months in duration after failing to be managed with maximal community support: one had an intractable psychotic illness that responded to clozapine, another a psychotic illness compounded by personality disorder and petty criminality whose behaviour improved following rehabilitation within a structured environment and the third remains an in-patient with a psychotic illness that responds poorly to treatment and is compounded by an antisocial personality. Five patients out of the six project clients who met the local Supervision Register criteria were not managed successfully by the ELCCT, in four cases after successful engagement with the team. These 'failures' of case management had some shared characteristics: a history of criminality and dangerous behaviour. continuing drug abuse and poor response to antipsychotic treatment. It is not clear what additional resources or expertise would have enabled the team to support these patients more effectively, although a closer working relationship with the substance misuse and forensic services would certainly have been welcomed by the case managers. One ELCCT client died in the first 18 months (of natural causes), which compared with two control patients (one of whom committed suicide).

The stresses inherent in the service model became increasingly apparent. Core staff were significantly burdened by the repeated crises that clients presented, the chronicity of clients' problems and knowledge of their socially deviant behaviours. Staff felt responsible for and aware of the team's 'failures' and reacted strongly to the introduction of the Supervision Register. Dealing with other agencies was often frustrating.

\section{Conclusion}

During its first 18 months the ELCCT developed a clinically credible way of working which gained respect from local clinicians and proved acceptable to its clients. The key service elements were specific treatments, practical flexible and readily accessible support, the therapeutic relationship between the case manager and the client and advocacy. Although effective with patients who had previously refused treatment, the ELCCT was not notably successful in managing treatment resistant patients, who often required prolonged periods of in-patient care before discharge to community settings.

\section{References}

BACHRACH, L. L. (1989) Case management: towards a shared definition. Hospital and Community Psychiatry. 10, 883884.

BURns, B. J. \& SANTos, A. B. (1995) Asserttve community treatment: an update of randomized trials. Psychiatric Services, 48, 669-675.

DEPARTMENT OF HEALTH (1994) Guidance on the dischange of mentally disordered people and their continuing care in the communtty. HSG $(94) 27$.

Houloway, F., Ouver, N., Counns, L., et al (1995) Case management for the mentally ill. A critical review of the Hterature. European Psychiatry, 10, 113-128.

KANTER, J. (1989) Clinical case management: definition. princtples, components. Hospttal and Communtty Psychiatry, 10, 361-368.

MCCARTHY, A. ROY, D. Houloway, F., et al (1995) Supervision registers and the care programme approach: a practical solution. Psychiatric Bulletin, 18. 195-199.

MARSHAU, M., LockwOOD, A. \& GATH, D. (1995) Soctal services case management for long-term mental disorders: a randomised controlled trial. Lancet, $\mathbf{8 4 5}$ $409-412$.

RYAN, P.. FORD, R. \& Curford, P. (1991) Case Management and Communtty Care. London: Rescarch and Development for Psychiatry.

Secretariss OF STATE POR HEALTH AND SOCLAL SECURTY WALES AND Scotund (1989) Carting for People. Communtty Care in the Next Decade and Beyond. London: HMSO.

*Frank Holloway, Consultant Psychiatrist. Bethlem and Maudsley NHS Trust Morag Murray, Clinical Manager, Brixton Sector, Clare Squire, Team Leader, East Lambeth Conttnuing Care Team; and Jerome Carson, Lecturer in Clinical Psychology. Institute of Psychiatry, London

*Correspondence

This paper is based on a talk given at the TAPS 9th Annual Conference in July 1994. 